\title{
COMPARATIVE STUDIES WITH DIFFERENT CYCLODEXTRIN DERIVATIVES IN IMPROVING THE SOLUBILITY AND DISSOLUTION OF SAQUINAVIR
}

\author{
BHARANI S SOGALI ${ }^{1 *}$, VIKRAM BN ${ }^{1}$, RAMANA MURTHY KV ${ }^{2}$
}

${ }^{1}$ Department of Pharmaceutics, Krupanidhi College of Pharmacy, Bengaluru - 560 035, Karnataka, India. ${ }^{2}$ Department of Pharmaceutics, Andhra University, Visakhapatnam, Andhra Pradesh, India. Email: bssogali@gmail.com

Received: 18 January 2018, Revised and Accepted: 16 February 2018

\section{ABSTRACT}

Objective: The present study was aimed to perform comparative studies with different cyclodextrin (CD) derivatives and to study the effect of different methods of preparation in improving the solubility and dissolution of saquinavir (SQV).

Methods: Phase solubility studies were performed with beta $C D(\beta C D)$, hydroxypropyl $\beta C D$, randomly methylated $\beta C D$, and sulfobutyl ether $\beta C D$ (SBE7 $\beta C D$ ). Complexes were prepared using physical mixture, coevaporation, kneading, spray drying, and freeze-drying techniques. For complexes prepared by spray drying, process parameters were optimized based on percentage yield. The prepared complexes were characterized using Fouriertransform infrared spectroscopy, differential scanning calorimetry, X-ray diffraction studies, nuclear magnetic resonance spectroscopy, and scanning electron microscopy. In vitro drug release study was conducted in phosphate buffer pH 6.8 and mean dissolution time (MDT) was calculated for all freeze-dried complexes.

Results: Phase solubility studies showed a linear relationship with an increase in CD concentration and phase diagrams were of $A_{L}$ type. Highest stability constant was observed with SQV-SBE7 $\beta C D(8281.28 / M)$. All characterization studies proved complexation. Among four CD derivatives, SQV complexed with SBE7 $\beta C D$ by freeze-drying showed maximum drug release and low MDT of 20.67.

Conclusion: Among different CDs, SBE7 $\beta C D$ proved as ideal CD derivative, and among different methods of preparations, freeze-drying method was found to be useful in improving the solubility and dissolution of SQV.

Keywords: Saquinavir, Cyclodextrin, Complexation, Freeze drying, Sulfobutyl ether beta cyclodextrin.

(C) 2018 The Authors. Published by Innovare Academic Sciences Pvt Ltd. This is an open access article under the CC BY license (http://creativecommons. org/licenses/by/4. 0/) DOI: http://dx.doi.org/10.22159/ajpcr.2018.v11i6.24836

\section{INTRODUCTION}

The improvement of oral bioavailability of poorly water-soluble drugs remains one of the most challenging aspects of drug development. Although there are many approaches available for improving dissolution rate and oral bioavailability, each method is having its own limitations. Complexation with cyclodextrins (CDs) is one of the widely used techniques for the enhancement of dissolution rate. Drug-CD complexation and improvement in solubility and dissolution rate are influenced by both nature of the CD (native or chemically modified, crystalline, or amorphous) and the method of complexation, namely, cogrinding, kneading, solid dispersion, solvent evaporation, coprecipitation, spray drying, or freeze drying [1-3]. The effectiveness of a method depends on nature of the drug and CD [4-7]. In many cases, spray drying and freeze drying were found to be more effective in improving the dissolution of poorly soluble drugs [8-12].

In the present research work, poorly soluble HIV-protease inhibitor, saquinavir (SQV) (BCS Class II drug) was selected which has poor water solubility and is reported to be an excellent P-gp and CYP3A substrate $[13,14]$. The oral bioavailability has been reported to be very low (0.7-4.0\%), and it is dependent on the dosage form used. SQV has been available as hard gelatin capsules, containing SQV mesylate (200 mg strength as SQV free base) [15]. Typically, it is dosed 2 times daily as five $200 \mathrm{mg}$ capsules in combination with ritonavir (100 mg twice daily). It is recommended that it should be taken with meals.

Although many earlier studies on CDs were reported for the enhancement of solubility and dissolution rate, very few comparative studies were reported $[16,17]$. Hence, in the present investigation, an attempt was made to compare the applicability of different CD derivatives, beta $C D(\beta C D)$, hydroxypropyl $\beta C D(H P \beta C D)$, randomly methylated $\beta C D$ (RM $\beta C D$ ), and sulfobutyl ether $\beta C D$ (SBE7 $\beta C D$ ) and influence of different methods of preparation in the development of complexes for improving dissolution.

\section{MATERIALS AND METHODS}

Materials

SQV was kindly purchased from Hetero Chemicals, Hyderabad, India. $\beta C D$ was gifted from Signet Pharma, India. HP $\beta C D$ and RM $\beta C D$ were gift samples received from Roquette Pharma, Italy. SBE7 $\beta C D$ was kindly gifted by Cydex pharmaceuticals, USA. All other chemicals used were of analytical grade.

\section{Methods}

\section{Phase solubility studies}

Phase solubility studies were performed as mentioned by Higuchi and Connors, 1965 [18] in pH 6.8 phosphate buffer to determine suitable CD derivative in solubility enhancement. Solubility studies were carried out by adding excess amounts of drug separately in quantities exceeding its aqueous solubility to $50 \mathrm{~mL}$ of buffer, containing increasing concentrations of CDs (2-12 mM). The resulting suspensions were shaken at room temperature for $72 \mathrm{~h}$ until equilibrium was established. The samples were filtered through a $0.45 \mu \mathrm{m}$ membrane filter (MillexHA filter units, Millipore) and suitably diluted with pH 6.8 phosphate buffer before analysis. All studies were performed in triplicate.

Apparent 1:1 stability constants were calculated from the straight-line portion of the phase solubility diagrams, according to the Equation 1. 


$$
\mathrm{K}_{\mathrm{a}: \mathrm{b}}=\frac{\text { Slope }}{\mathrm{S}_{0}(1-\text { Slope })}
$$

Where $\mathrm{S}_{0}$ is the solubility of the drug in examined buffer solution in the absence of ligand.

\section{Preparation of drug-CD complexes [8,19-21]}

In the present work, drug-CD complexes were prepared using physical mixing, coevaporation, kneading, spray drying, and freeze drying.

\section{Physical mixing}

Drug and CDs at equimolar ratio (1:1) were weighed and mixed in a mortar by geometric dilution method for sufficient time $(\sim 5 \mathrm{~min})$ to obtain a homogenous powder blend, passed through sieve no. 80 , and stored in a sealed glass vials and kept in desiccator over fused calcium chloride until further use.

\section{Kneading}

CDs were wetted in a mortar with a minimum volume of water:ethanol mixture (1:1) until a paste was obtained. The required amount of drug was slowly added, and the slurry was kneaded for about $45 \mathrm{~min}$. During this process, a suitable quantity of solvent was added to maintain optimum consistency. Further, the products were dried at $40^{\circ} \mathrm{C}$ to constant weight, passed through sieve no. 80 , and stored in a desiccator until further evaluation.

\section{Solvent evaporation}

Required quantities of drug and CD were dissolved in sufficient quantity of water:ethanol solvent mixture (1:1) and evaporated on a water bath at $50^{\circ} \mathrm{C}$ with stirring. Each solid product was sieved through $\# 80$ and stored in a desiccator

\section{Spray drying [22-24]}

In spray drying, characteristic properties of powders such as particle size and shape obtained are influenced by the nozzle, the viscosity of the feeding solution, and the outlet temperature $\left(\mathrm{T}_{\text {out }}\right)$, and the latter being dependent on the two spray drying process variables: Inlet temperature $\left(\mathrm{T}_{\mathrm{in}}\right)$ and solution flow. To select best optimizing conditions, SQV with $\beta C D$ combination was used and the same process conditions were applied with other CDs used in complex formation. For optimization, the influence of solution flow rate and $\mathrm{T}_{\text {in }}$ was studied, and the solutions were atomized at three different flow rates $(2,5$. and 10 $\mathrm{ml} / \mathrm{min})$ using fixed values for compressed air $(500 \mathrm{l} / \mathrm{h})$ and aspirator $\left(40 \mathrm{~m}^{3} / \mathrm{h}\right.$ ). Two $\mathrm{T}_{\text {in }}$ values were used: $55^{\circ} \mathrm{C}$ and $70^{\circ} \mathrm{C}$. $\mathrm{T}_{\text {out }}$ was kept constant at a temperature of $50^{\circ} \mathrm{C}$.

Spray drying was performed using Labultima LU22 spray dryer for the preparation of inclusion complexes. Equimolar ratio of drug and CDs was dissolved in sufficient quantity of ethanol and water mixture (1:1). The solutions were atomized at a flow rate $2 \mathrm{ml} / \mathrm{min}$ using fixed values for compressed air $(500 \mathrm{~L} / \mathrm{h})$ and aspirator $40-50 \mathrm{~m}^{3} / \mathrm{h}$ with $\mathrm{T}_{\text {in }}$ value of $70^{\circ} \mathrm{C}$, corresponding to a $\mathrm{T}$ of $48^{\circ} \mathrm{C}$. After spray drying, each resulting powder was collected by cyclone separation and transferred to glass vials. After spray drying, all complexes were kept in an oven at $40^{\circ} \mathrm{C}$ for $24 \mathrm{~h}$ to remove traces of moisture present in the complexes.

Freeze drying/lyophilization

Required quantity of CD was dissolved in sufficient quantity of water, and required quantity of drug was added and dispersed. The dispersion was kept under magnetic stirring at $200 \mathrm{rpm}$ for $72 \mathrm{~h}$ in closed vials for complex formation which resulted in the formation of a clear solution. The resulting solution was fast frozen at $-20^{\circ} \mathrm{C}$ using liquid nitrogen and dried at $-50^{\circ} \mathrm{C}$ and 0.0070 mbar pressure in a freeze dryer (Model MODUL YOD 230, Thermo Electron Corporation, India) for $48 \mathrm{~h}$. The obtained freeze-dried product in the glass vial was stored in a desiccator.

\section{Determination of moisture content}

The residual moisture content of the spray-dried complexes was determined through loss on drying using a HR83 halogen moisture analyzer (Mettler-Toledo, India). A sample of $0.5 \mathrm{~g}$ was dried at $105^{\circ} \mathrm{C}$ for $5 \mathrm{~min}$

\section{In vitro release characteristics of complexes}

Dissolution experiments were carried out in triplicate $(n=3)$ with an USP XXIII paddle apparatus in $900 \mathrm{ml}$ of $\mathrm{pH} 6.8$ phosphate buffer at $37^{\circ} \mathrm{C}$ using a rotation speed of $50 \mathrm{rpm}$. In each study, drug-CD complex equivalent to $100 \mathrm{mg}$ of drug was used. $5 \mathrm{ml}$ sample was withdrawn at intervals of 5, 15, 30, 45, and 60 min using a syringe fitted with prefilter $(0.45 \mu \mathrm{m})$. An equal amount of fresh dissolution medium maintained at the same temperature was replaced immediately after withdrawal of the test sample. Test samples were suitably diluted wherever necessary, and the absorbance was measured as per the analytical procedures described. The mean percentage of drug dissolved and the standard deviations (SD) were calculated.

\section{Drug-excipient interaction studies}

Drug-excipient interaction studies were conducted for SQV, pure CDs, physical mixtures, and freeze-dried complexes to gain insight into interactions between drug and respective CDs in the complexed form.

\section{Fourier-transform infrared (FTIR) spectroscopy}

FTIR spectra were used to identify the formation of complex. Samples were analyzed by potassium bromide pellet method in an IR spectrophotometer (Shimadzu, FTIR 1300) in the region between 400 and $4000 / \mathrm{cm}$. Complex formation was evaluated by comparing the IR spectra of the solid complex with drug. For comparison purposes, FTIR spectra were obtained for $S Q V$, each $\beta C D$ being studied as well as physical mixtures of both drugs with each $\mathrm{CD}$.

\section{Differential scanning calorimetry (DSC)}

The thermal behavior of SQV and CD inclusion complexes was studied using DSC to confirm the formation of solid complex. When guest molecules are incorporated in the CD cavity or in the crystal lattice, their melting, boiling, and sublimation points are usually shifted to a different temperatures or disappear within the temperature range. The samples were heated from $0^{\circ} \mathrm{C}$ to $350^{\circ} \mathrm{C}$ at a heating rate of $10^{\circ} \mathrm{C} / \mathrm{min}$ under a nitrogen flow and flowing at a rate of $40 \mathrm{~mL} / \mathrm{min}$ through the DSC cell.

\section{Powder X-ray diffraction (PXRD) study}

XRD of inclusion complexes and the pure drug were performed to identify the interaction of the drug with CDs using a PW 1720 X-ray generator and a PW 1710 diffractometer control (Philips Electronic

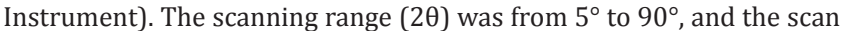
step and scan speed were $0.04^{\circ}$ and $0.02^{\circ} / \mathrm{s}$, respectively.

\section{Nuclear magnetic resonance (NMR) spectroscopy}

${ }^{1} \mathrm{H}$-NMR studies were conducted to determine the electronic interactions between drug and CDs and it was studied using Bruker AM400 spectrophotometer. Samples were prepared by dissolution of the drug in methanol as a solvent for RTV. ${ }^{1} \mathrm{H}-\mathrm{NMR}$ spectra of inclusion complexes and pure components were recorded. Chemical shifts were reported in ppm $(\delta)$ downfield from tetramethylsilane (internal reference).

\section{Scanning electron microscopy (SEM)}

The morphological properties of the SQV, physical mixture, and freezedried powders ofSQV-SBE7 $\beta C D$ complex were characterized by scanning electronic microscopy (Cambridge instrument: Stereoscan 360).

\section{RESULTS AND DISCUSSION}

\section{Phase solubility studies}

The solubility of SQV increased linearly as a function of $\mathrm{CD}$ concentration. The phase solubility profiles showed a linear increase in complexation of $S Q V$ with an increase in $C D$ concentration with all four 
CDs, displaying type $A_{\llcorner}$phase diagrams according to the classification by Higuchi. The correlation coefficient of the linear regression line for each of the phase solubility curves was $>0.99$, indicating a good fit for all complexes.

The slope of the lines was found to be 0.2855 for $\beta C D, 0.5954$ for $\mathrm{HP} \beta C D, 0.7711$ for RM $\beta C D$, and 0.7762 for SBE7 $\beta C D$. As the slope of the line is less than unity, it was assumed that the increase in the solubility observed was due to the formation of a 1:1 molar complex.

The stability constants $\left(\mathrm{K}_{1.1}\right)$ of SQV with each CD were calculated using Equation 1 and given in Table 1. The calculated values were 906.6/M for $\beta C D, 3706.2 / M$ for $H P \beta C D, 6899.46 / M$ for RM $\beta C D$, and 8281.28/M for SBE7 $\beta C D$. The $\mathrm{K}_{1: 1}$ value for SQV -SBE7 $\beta C D$ complex was found to be $8281.28 / \mathrm{M}$ which is 9 -fold higher than $\beta C D$, 2.23-fold higher than $\mathrm{HP} \beta C D$, and 1.2-fold higher than RM $\beta C D$, indicating that SBE7 $\beta C D$ has superior SQV complexing efficiency. This may potentially be due to $\mathrm{SQV}$ interacting with the anionically charged moiety of the SBE7 $\beta C D$.

In the present study, the enhancement of SQV solubility was highly dependent on the type of $\mathrm{CD}$ used. Based on the phase solubility diagrams, SBE7 $\beta C D$ is more effective in solubilizing SQV in $\mathrm{pH} 6.8$ phosphate buffer compared to other CDs. The order of solubilizing capacity of CDs was as follows: SBE7 $\beta C D>R M \beta C D>H P \beta C D>\beta C D$. The different complexation constants found for different $C D$ molecules indicated that the derivative groups on CDs appear to play an important role in the incorporation of $S Q V$ into $C D$ cavity since much higher complexation constants were obtained with RM $\beta C D$ and SBE7 $\beta C D$.

\section{Preparation of drug-CD complexes}

The phase solubility studies carried out with different CDs on both drugs indicated the formation of complex in 1:1 molar ratio. Drug-CD complexes were prepared with all the four CDs for SQV, whereas HP $\beta C D$ and RM $\beta C D$ were used for ritonavir using four different methods of preparation. In each method, 4-5 g of drug-CD complexes was prepared at equimolar ratio.

\section{Study of spray drying process conditions}

The result of the determination of the yield for each one of the experimental conditions is shown in Table 2 . The yield obtained under varying conditions of $\mathrm{T}_{\text {in }}$ and flow rate was in the range of $37-62 \%$. Yield was significantly influenced by flow rate rather than $T_{\text {in }}$ in which lower flow rate resulted in higher yield. No significant difference in yield was observed between the two $\mathrm{T}_{\text {in }}$ values. Earlier reports also confirmed this result in which higher flow rates resulted in low yields in the range of $40-50 \%$ [25-27]. These low yield values could be justified by the biggest number of atomized particles that adhere more to the walls of the drying chamber and its removal for the cyclone collector being more difficult.

Hence, a flow rate of $2 \mathrm{ml} / \mathrm{min}$ with a $\mathrm{T}_{\text {in }}$ of $55^{\circ} \mathrm{C}$ was found to be optimized conditions which gave the highest yield of $62 \%$ drug-CD complexes and these two conditions were used for the preparation of drug-CD complexes by spray drying technique.

\section{Determination of moisture content}

Moisture content for all the complexes was in the range of $0.9-2.5 \%$ (Table 3) SQV complex prepared with SBE7 $\beta C D$ showed slightly higher moisture content compared to other CDs. Earlier reports also indicated higher moisture content for complexes prepared with SBE7 $\beta C D$ due to its hygroscopic nature [28]

\section{Dissolution studies of SQV-CD complexes}

Dissolution characterizes of a dosage form have a direct bearing on its efficacy, especially when the medicament is poorly soluble or insoluble in aqueous fluids. In general, for poorly soluble drugs, difficulties are usually encountered in selecting a suitable dissolution medium with good discriminating power. Dissolution of drugs from solid dosage form is a key parameter in assessing the release rate, release mechanism, and kinetics at product development stage. SQV capsules and tablets are official in IP and USP. Citrate buffer ( $\mathrm{pH}$ 3.0) is mentioned as dissolution medium in all official books and the FDA listed drugs [29,30]. However, this medium is not suitable as discriminating medium as $\mathrm{SQV}$ is highly soluble in this media as per studies conducted by Pathak et al. [31] Hence, $\mathrm{pH}$ of the dissolution media was selected based on discriminating ability, and $\mathrm{pH}$ of upper gastrointestinal for $\mathrm{SQV}$, i.e., $\mathrm{pH} 6.8$ phosphate buffer.

All dissolution studies were performed for $60 \mathrm{~min}$ as the objective of the present investigation was to achieve the complete drug release within this period. Drug-CD complexes failing to achieve this objective were not studied further. Drug-CD complex equivalent to $100 \mathrm{mg}$ of the drug was used for dissolution study in each case, and each study was replicated for 3 times and average values with SD are reported in tables.

From the dissolution studies, it was observed that only $20.82 \%$ dissolution of pure $S Q V$ was observed in $60 \mathrm{~min}$. The dissolution of SQV with $\beta C D, H P \beta C D, R M \beta C D$, and SBE7 $\beta C D$ physical mixtures showed a release of $27.21-38.44 \%$ of SQV. Complexes prepared by kneading method showed drug release of $36.57-47.29 \%$ and that are prepared with coevaporation method showed $37.6-48.05 \%$ with all the four CDs. Among different methods of preparation, spray-dried (37.7580.63\%) and freeze-dried (38.74-99.27\%) complexes showed higher drug release in $60 \mathrm{~min}$ of dissolution study. Among all complexes, SQV-SBE7 $\beta C D$ complexes prepared by freeze-drying method showed complete drug release within the stipulated time.

All inclusion complexes showed improvement of drug release compared to $\mathrm{SQV}$ alone except for physical mixtures where the enhancement is negligible. Complexes prepared by spray drying and freeze-drying methods showed marked enhancement in dissolution compared to other methods for all CDs. The order of drug release from complexes prepared by different methods was $\mathrm{FD}>\mathrm{SD}>\mathrm{COE}>\mathrm{KN}>\mathrm{PM}$ for $\beta \mathrm{CD}$ and $\mathrm{HP} \beta C D$. This may be due to the heat used in coevaporation which helps in complex formation. In case of RM $\beta C D$ and SBE7 $\beta C D$, kneading method

Table 1: Stability constants of SQV with four CDs

\begin{tabular}{lll}
\hline Type of CD & $\mathbf{K}_{1: 1} / \mathbf{M}$ & Phase diagram \\
\hline$\beta C D$ & 906.80 & $\mathrm{~A}_{\mathrm{L}}$ type \\
HP $\beta C D$ & 3706.20 & $\mathrm{~A}_{\mathrm{L}}$ type \\
RM $\beta C D$ & 6899.46 & $\mathrm{~A}_{\mathrm{L}}$ type \\
SBE7 $\beta C D$ & 8281.28 & $\mathrm{~A}_{\mathrm{L}}$ type \\
\hline
\end{tabular}

SQV: Saquinavir, CDs: Cyclodextrins, $\beta C D$ : Beta cyclodextrin,

HPßCD: Hydroxypropyl beta cyclodextrin, RM $\beta C D$ : Randomly methylated beta cyclodextrin, SBE7 $\beta C D$ : Sulfobutyl ether beta cyclodextrin

Table 2: \% Yield of SQV- $\beta C D$ complexes under different experimental conditions

\begin{tabular}{lll}
\hline $\begin{array}{l}\text { Air inlet } \\
\text { temperature }\left({ }^{\circ} \mathbf{C}\right)\end{array}$ & Solution flow rate $(\mathrm{ml} / \mathbf{m i n})$ & \% yield \\
\hline 55 & 2 & 62.0 \\
& 5 & 50.5 \\
70 & 10 & 37.5 \\
& 2 & 61.8 \\
& 5 & 50.0 \\
& 10 & 37.0 \\
\hline
\end{tabular}

SQV: Saquinavir, $\beta C D$ : Beta cyclodextrin

Table 3: Moisture content of spray-dried complexes

\begin{tabular}{lll}
\hline Drug & Type of CD & Moisture content (mean \pm SD) $(\mathbf{n}=\mathbf{3})$ \\
\hline SQV & $\beta C D$ & $1.01 \pm 0.50$ \\
& HP $\beta C D$ & $1.23 \pm 0.45$ \\
& RM $\beta C D$ & $1.15 \pm 0.50$ \\
& SBE7 $\beta C D$ & $2.51 \pm 0.42$ \\
\hline
\end{tabular}

*SD: Standard deviation. SQV: Saquinavir, CD: Cyclodextrin, $\beta C D$ : Beta cyclodextrin, HP $\beta C D$ : Hydroxypropyl beta cyclodextrin, RM $\beta C D$ : Randomly methylated beta cyclodextrin, SBE7 $\beta C D$ : Sulfobutyl ether beta cyclodextrin 
showed higher drug release than coevaporation. When the effect of type of CD was observed, complexes prepared with SBE7 $\beta C D$ showed good enhancement in dissolution. The improvement in dissolution follows the order: $S B E 7 \beta C D>R M \beta C D>H P \beta C D>\beta C D$. Enhanced drug release with $S B E 7 \beta C D$ could be attributed to its charged groups which are appropriately spaced from the cavity and also increased in the hydrophobicity around the cavity due to the presence of alkyl chains.

$\mathrm{DE}_{10}$ and $\mathrm{T}_{50}$ were calculated only for spray-dried and freeze-dried products as the drug release was very slow for other methods, physical mixing, kneading, and coevaporation, and some of the complexes did not show even $50 \%$ of drug release. All drug-CD complexes showed higher $\% \mathrm{DE}_{60}$ and $\mathrm{DP}_{30}$ values compared to pure drug. Among different CDs used in the study, complexes prepared with SBE7 $\beta C D$ showed higher $\% \mathrm{DE}_{60}$ and $\mathrm{DP}_{30}$. When the method of preparation was observed, freeze-dried and spray-dried products exhibited higher $\% \mathrm{DE}_{60}$ and $\mathrm{DP}_{30}$ values than the physical mixture, kneaded and coevaporated products, and SQV. Kneaded products showed higher $\% \mathrm{DE}_{60}$ and $\mathrm{DP}_{30}$ compared to coevaporated products with SQV-RM $\beta C D$ and SBE7 $\beta C D$. On the contrary, coevaporated products showed higher $\% \mathrm{DE}_{60}$ and $\mathrm{DP}_{30}$ than kneaded products with $\beta \mathrm{CD}$ and $\mathrm{HP} \beta \mathrm{CD}$ complexes. Higher $\% \mathrm{DE}_{10}$ and lower $\mathrm{T}_{50}$ values were observed with spray-dried and freeze-dried complexes prepared with SBE7 $\beta C D$. The extent of the enhancement of the dissolution was found to be dependent on the preparation method and the type of CD since SQV-SBE7 $\beta C D$ complex prepared by freeze drying exhibited 4.14-fold higher $\mathrm{DE}_{60}$ value and two-fold increase in $\mathrm{DP}_{30}$ values compared to pure SQV.

Mean dissolution time (MDT) values were calculated for freezedried complexes as they gave maximum drug release. All freezedried complexes showed a decrease in MDT compared to SQV alone. The lowest MDT was observed with complexes prepared by freeze drying with SBE7 $\beta C D$ (Fig. 1). The lower the MDT value, the faster the drug release. Very high MDT was found for SQV, 238.01 where as SQV- SBE7 $\beta C D$ complex gave very low MDT of 20.67 indicated the inclusion of SQV with SBE7 $\beta C D$ by freeze-drying method enhanced the dissolution rate. The enhancement with freeze-dried complexes may be due to increased interaction and conversion of drug into highly amorphous state in freeze-drying method.

\section{Drug-excipient interaction studies}

FTIR studies

FTIR studies of SQV exhibited peaks at $3529 / \mathrm{cm}$ for OH stretching, $3100 / \mathrm{cm}$ for $\mathrm{NH}_{2}$ stretching, $1622 / \mathrm{cm}$ for $\mathrm{C}=0$ stretching, and $3381 / \mathrm{cm}$ for NH stretching which confirms the structure of SQV. The spectra of RM $\beta C D$ showed prominent peaks at $3400.02 / \mathrm{cm}$ for $\mathrm{O}-\mathrm{H}$ stretch and $2923.07 / \mathrm{cm}$ for C-H aliphatic stretch. IR spectra of physical mixture of

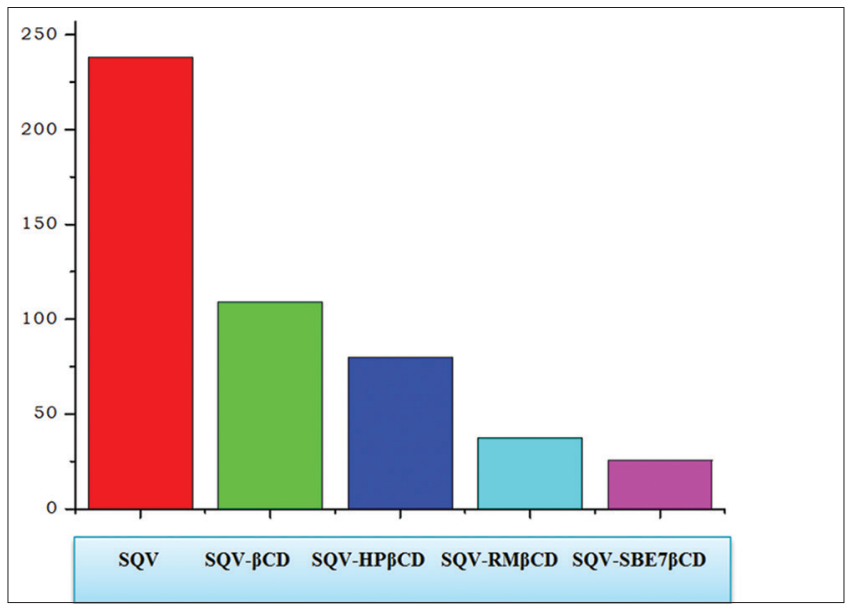

Fig. 1: Bar diagram of mean dissolution time values for saquinavir-cyclodextrin complexes prepared by freeze-drying method
SQV-RMBCD showed broadening of the peak from 3150 to $3500 / \mathrm{cm}$ and increase in the intensity of C-H aliphatic stretch at 2935.76/ cmindicates an interaction between $\mathrm{SQV}$ and RM $\beta \mathrm{CD}$.

The spectra of SBE7 $\beta C D$ showed prominent peaks at $3425 / \mathrm{cm}$ for $\mathrm{O}-\mathrm{H}$ stretch, $2936.7 / \mathrm{cm}$ for C-H stretch, and $1647.2 / \mathrm{cm}$ for C=0 stretch. The peaks of physical mixture of SBE7 $\beta C D$ were smoothened compared to that of SQV indicating complexation between SQV and SBE7 $\beta C D$. FTIR spectrum of SQV-SBE7 $\beta C D$ freeze-dried complex shows characteristic broad peak at 3291.89/cm (Fig. 2). This shift and broadening of peak indicated complexation between SQV and SBE7 $\beta C D$.

The FTIR spectrums of complexes showed a substantial decrease in intensity and broadening compared to that of SQV. This result suggested the formation of a new supramolecular compound. In addition, no new peaks were observed in the spectra of SQV-CD complex systems, indicated that no new chemical compounds were created in the complex formation. Thus, the FTIR spectra indicated that SQV is partially included into the $\mathrm{CD}$ to form inclusion complex.

\section{DSC studies}

The DSC thermogram of SQV showed an endothermic peak at $239^{\circ} \mathrm{C}$ which was corresponding to its melting point. The DSC spectra of RM $\beta C D$ showed a broad endothermic peak in the range of $80-100^{\circ} \mathrm{C}$ which can be attributed to desolvation. The physical mixture of SQV and RM $\beta C D$ showed an endothermic peak at $233^{\circ} \mathrm{C}$ and freeze-dried complex showed broadening of endothermic peak in the range $226-260^{\circ} \mathrm{C}$, respectively, due to the formation of inclusion complex. The DSC thermogram for SBE7 $\beta C D$ showed at $270^{\circ} \mathrm{C}$, whereas the physical mixture of SQV and SBE7 $\beta C D$ showed very less intense peak which indicated good interaction happened in physical mixing itself with SBE7 $\beta C D$ (Fig. 3). Freeze-dried complex showed reduced intensity of endothermic peak and shifted to $237.05^{\circ} \mathrm{C}$ due to the carrier induced drug amorphous conversion.

\section{NMR spectroscopy}

Only ${ }^{1} \mathrm{H}-\mathrm{NMR}$ spectroscopy can afford the most direct evidence for a true inclusion complex formation by evidencing interactions between guest molecules and the host CDs. All the proton signals in the $1 \mathrm{H}$-NMR spectrum of the pure SQV were observed at $1.26 \mathrm{ppm}$ which represents aliphatic amine, at 6.7-6.9 ppm which represents multiplet aromatic protons and other prominent chemical shifts were observed at 2.76 and $4.7 \mathrm{ppm}$. Proton signals for benzene rings in SQV were represented $\delta_{H}$ at $6.7 \mathrm{ppm}, 6.9 \mathrm{ppm}, 7.1 \mathrm{ppm}, 7.75 \mathrm{ppm}, 7.9 \mathrm{ppm}, 8.05 \mathrm{ppm}, 8.1 \mathrm{ppm}$, $8.14 \mathrm{ppm}$, and $8.5 \mathrm{ppm} .{ }^{42} \delta_{\mathrm{H}}$ at $4.7 \mathrm{ppm}$ represented the signal of water (Fig. 4).

The insertion of SQV molecule into CD cavity was demonstrated by changes in ${ }^{1} \mathrm{H}$-NMR chemical shift values. NMR spectra clearly indicated interactions between SQV and $\mathrm{H}-3$ and $\mathrm{H}-5$ protons belonging to the host CD and pointed toward the interior of the cavity. Significant changes were observed in the signal due to $\mathrm{H}-3$ and $\mathrm{H}-5$, whereas $\mathrm{H}-1$, $\mathrm{H}-2, \mathrm{H}-4$, and $\mathrm{H}-6$ (located outside the cavity) were relatively unshielded by SQV. The shifts observed for the CD protons were indicative of the occurrence of an inclusion of SQV into the CD cavity. In case of SQV, a significant upfield shift for the resonance of the protons of the two aromatic cycles of SQV (isoquinoline ring and phenyl ring) was observed in the presence of $\mathrm{CD}$. This upfield shift noted for the resonance of aromatic protons indicated that the two aromatic cycles of SQV were mainly involved in the formation of the complex, suggesting that both isoquinoline and phenyl ring moieties would be expected to be included with in CD cavity due to their hydrophobicity and satisfactory geometry. The study clearly showed a significant reduction in signal intensity with SQV-SBE7 $\beta C D$ complex and shifting of peaks indicating SQV completely included with SBE7 $\beta C D$ than with other CDs.

\section{XRD studies}

In the X-ray diffractogram of SQV, sharp peaks at a diffraction angle $(2 \theta)$ of $12^{\circ}, 16^{\circ}, 17^{\circ}, 18^{\circ}, 19^{\circ}$, and $20^{\circ}$ were present which suggested that 


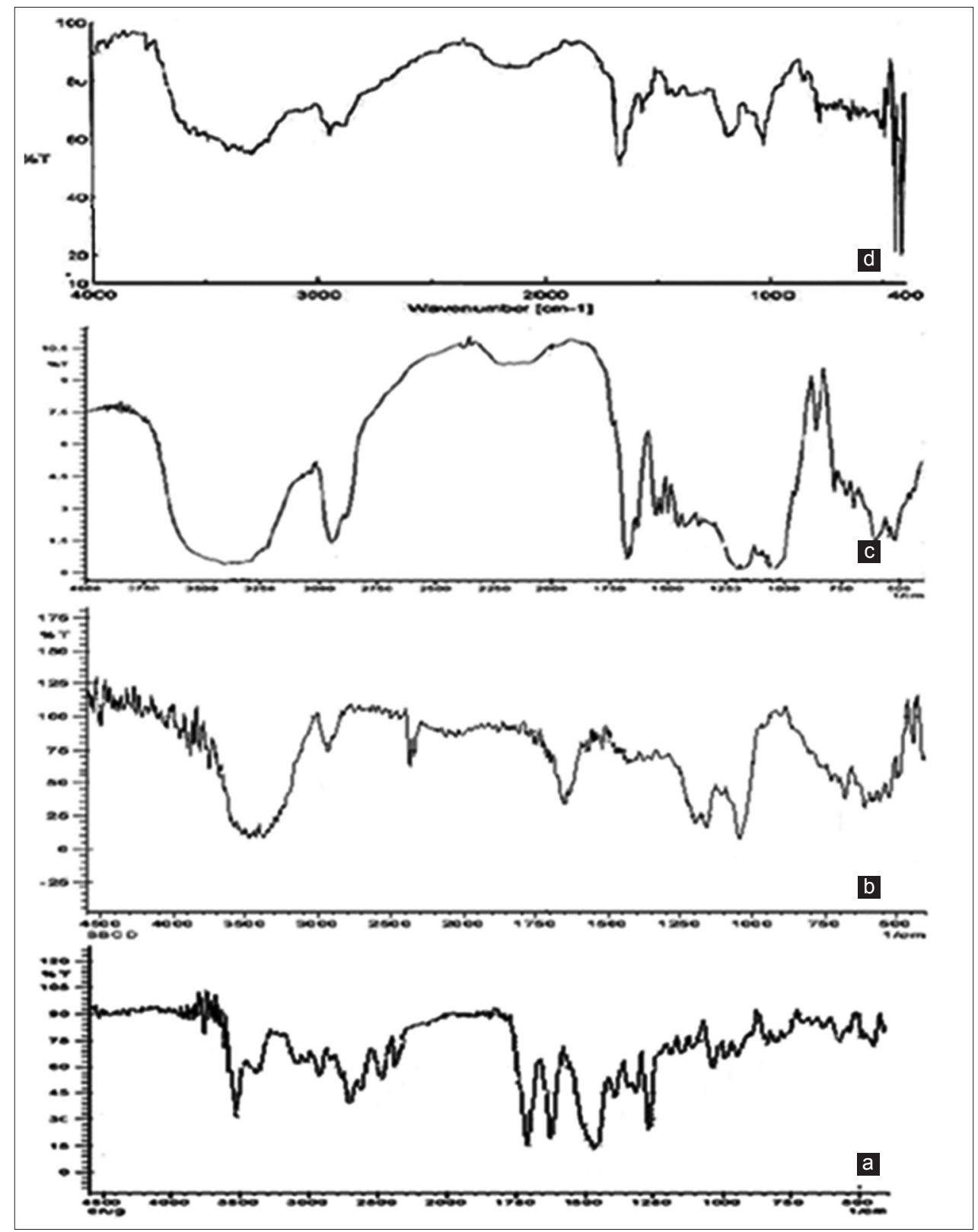

Fig. 2: Fourier-transform infrared spectra of (a) saquinavir (SQV) (b) sulfobutyl ether beta cyclodextrin (SBE7 $\beta C D)$ (c) SQV-SBE7 $\beta C D$ physical mixture (d) SQV-SBE7 $\beta C D$ complex prepared by freeze drying

the drug is present as a crystalline material (Fig. 5). In the freeze-dried complexes prepared with RM $\beta C D$ and SBE7 $\beta C D$, the presence of free crystalline drug was revealed by few sharp peaks of low intensity at $21^{\circ}$, which emerged on the diffuse background due to the amorphous CDs, indicating loss of crystallinity in the drug and due to reduction of size of particles during the process of freeze drying which indicated the formation of inclusion complex. It was observed that the intensity of crystalline peaks of freeze-dried complex of SQV-SBE7 $\beta C D$ was reduced to a greater extent compared to other $\mathrm{CD}$ derivatives. This may be due to the better interaction between the drug and SBE7 $\beta C D$ which converted the drug into amorphous form.

\section{SEM}

The SEM of SQV and SQV-SBE7 $\beta C D$ complexes prepared by spray drying and freeze drying is shown in Fig. 6. SQV has appeared as irregular shaped crystals and was constituted by relatively bulky particles, with smaller ones adhered on its surface. Spray-dried samples appeared with uniform spherical-shaped particles, and freeze-dried samples appeared as elongated particles. The drastic change of the particle's shape and aspect in the spray-dried and freeze-dried samples was indicative of the presence of a single phase, thus correlating with PXRD observations.

\section{CONCLUSION}

Comparative studies of SQV-CD complexes with different CDs such as $\beta C D, H P \beta C D, R M \beta C D$, and SBE7 $\beta C D$ for improving the bioavailability of BCS Class II drug and SQV were carried out. Simultaneously, the influence of the method of preparation and finding out best CD derivative in improving solubility and dissolution of SQV were studied. With the help of phase solubility studies, quantities of CDs were minimized in the preparation of drug-CD complexes. Formation of inclusion complexes was established with the help of FTIR, DSC, ${ }^{1} \mathrm{H}-\mathrm{NMR}$, XRD, and SEM studies. Among different CDs, SBE7 $\beta C D$ proved as best $\mathrm{CD}$ derivative in forming complex with $\mathrm{SQV}$, and among different methods of preparations, freeze-drying method was found to be 
useful in improving the solubility and dissolution. Further studies on optimized complex form of SQV may lead to reduction of the dose of SQV due to improved bioavailability.

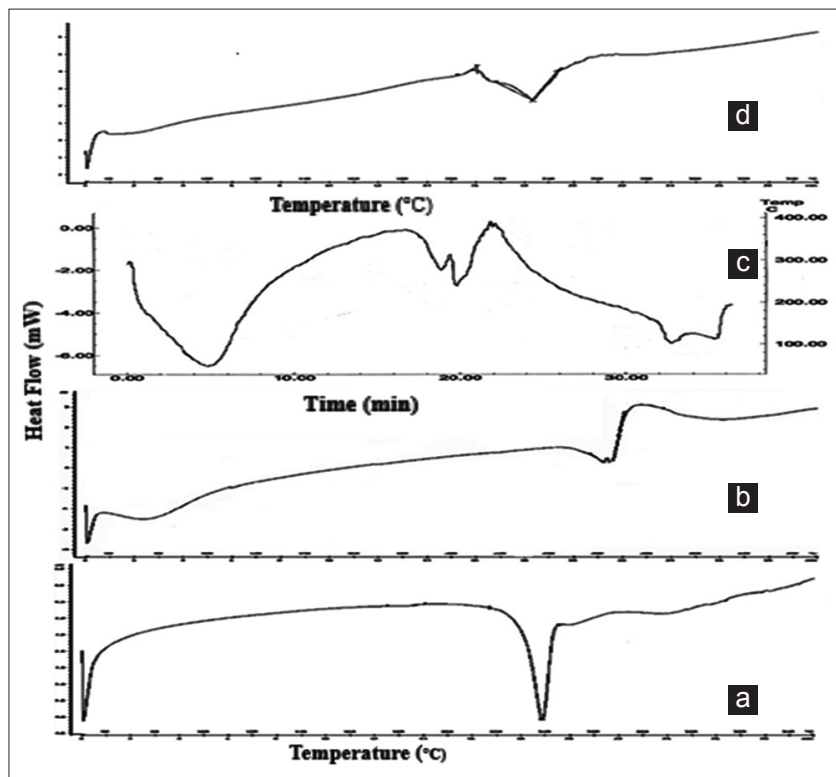

Fig. 3: Differential scanning calorimetry spectra of (a) saquinavir (SQV) (b) sulfobutyl ether beta cyclodextrin (SBE7ßCD) (c) SQVSBE7 $\beta C D$ physical mixture (d) SQV-SBE7 $\beta C D$ complex prepared by freeze drying

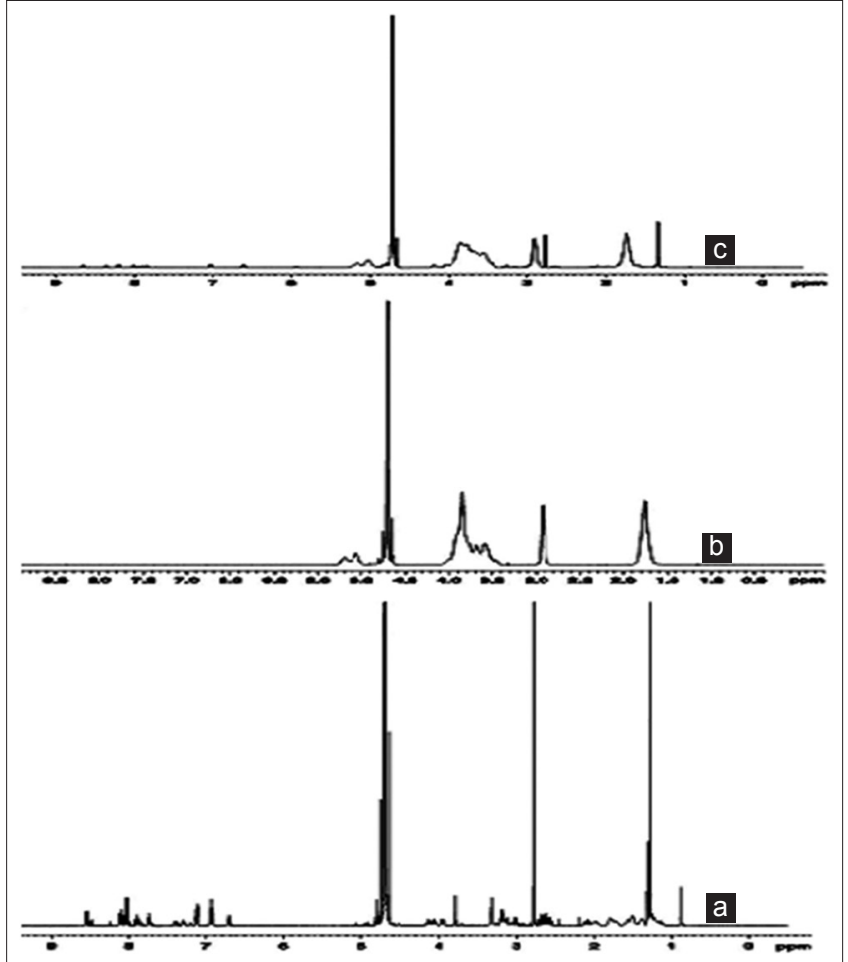

Fig. 4: ${ }^{1} \mathrm{H}$ nuclear magnetic resonance spectra of (a) saquinavir (SQV) (b) sulfobutyl ether beta cyclodextrin (SBE7ßCD) (c) SQVSBE7 $\beta C D$ complex prepared by freeze drying

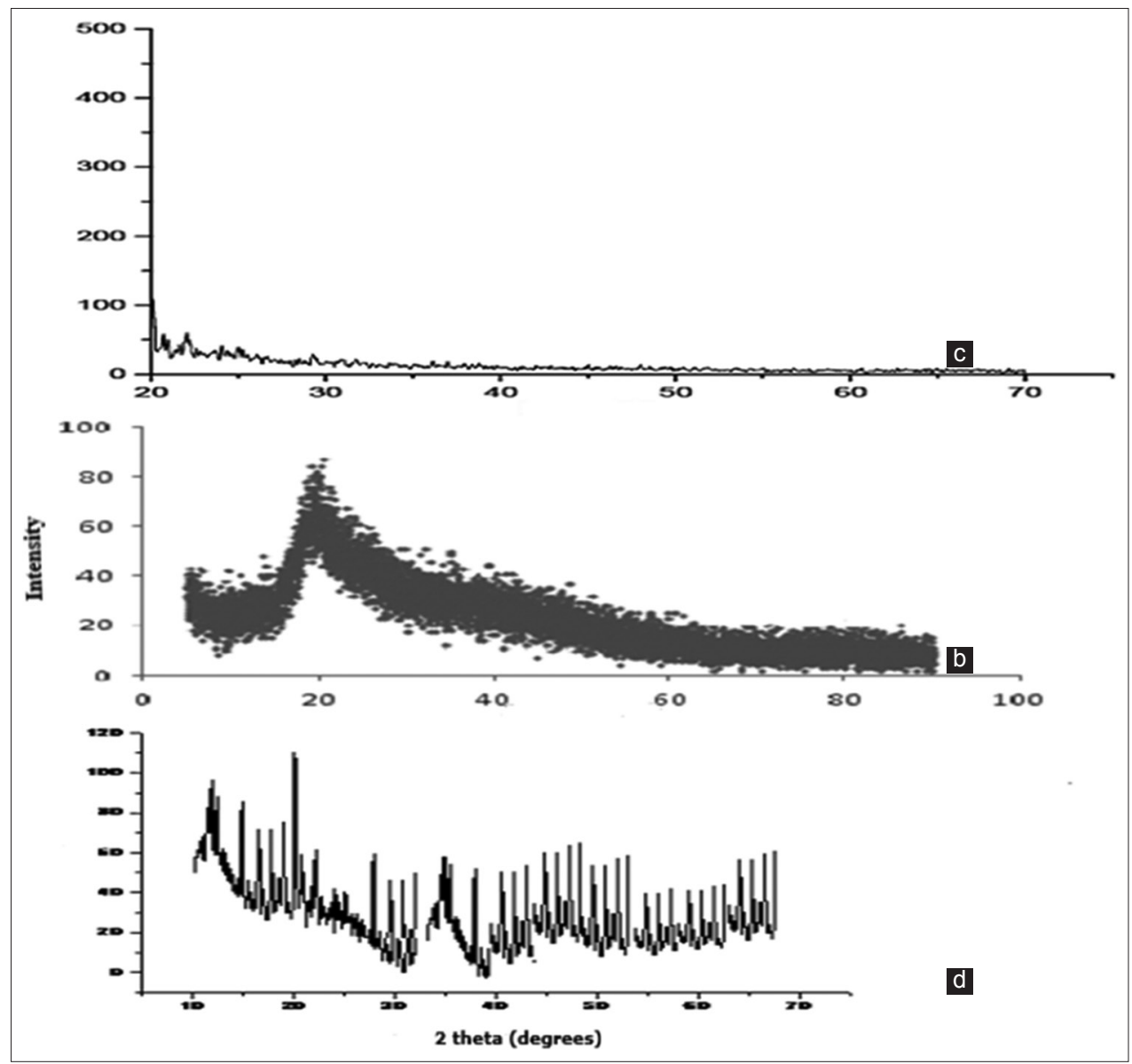

Fig. 5: X-ray diffraction patterns of (a) saquinavir (SQV) (b) sulfobutyl ether beta cyclodextrin (SBE7 $\beta C D)$ (c) SQV-SBE7 $\beta C D$ complex prepared by freeze drying 

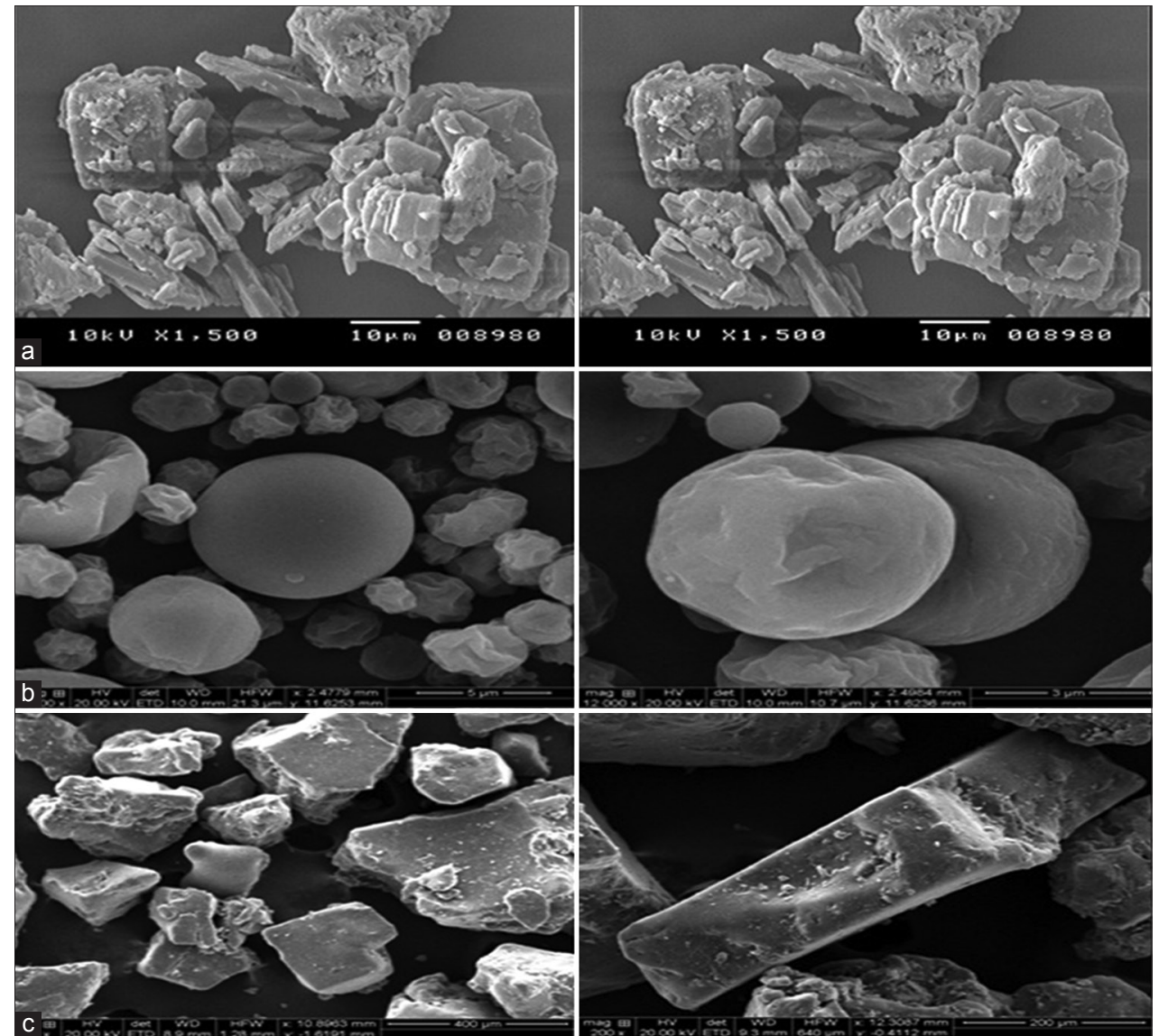

Fig. 6: Scanning electron microscopy images of (a) saquinavir (SQV) (b) SQV- sulfobutyl ether beta cyclodextrin (SBE7 $\beta C D)$ complex prepared by spray drying (c) SQV-SBE7 $\beta C D$ complex prepared by freeze drying

\section{AUTHORS' CONTRIBUTIONS}

All authors have contributed in completion of this research work.

\section{CONFLICT OF INTEREST}

Authors have none to declare.

\section{REFERENCES}

1. Loftsson T, Brewster ME, Derendorf H, Bodor N. 2-Hydroxypropyl$\beta$-cyclodextrin: Properties and usage in pharmaceutical formulations. Pharm Ztg Wiss 1991;4:5-10.

2. Arora P, Singh J, Chadha R. Physicochemical characterization and evaluation of telmisartan: Hydroxypropyl- $\beta$-cyclodextrin: Tween 80 inclusion complex. Int J Pharm Pharm Sci 2017;9:51-8.

3. Gera S, Cheruvu S, Zakkula A, Sampathi S. Synthesis and evaluation of olmesartan medoxomil complex with sbe7 $\beta$-cd for enhanced dissolution and bioavailability. Int J Pharm Pharm Sci 2016;8:333-43.

4. Sogali BS, Sushant MS, Murthy KV. Comparative evaluation of cyclodextrins in improving the dissolution of ritonavir. Int J Pharm 2016;6:159-76.

5. Chowdary KP, Nalluri BN. Nimesulide and beta-cyclodextrin inclusion complexes: Physicochemical characterization and dissolution rate studies. Drug Dev Ind Pharm 2000;26:1217-20.

6. Palmeiri GF, Angeli DG, Giovannnucci G, Martelli S. Inclusion of methoxytropate in beta- and hydroxyl propyl beta cyclodextins: Comparision of preparation methods. Drug Dev Ind Pharm 1997; 23:27-37.

7. Palmieri GF, Wehrle P, Stamm A. Inclusion of vitamin D2 in $\beta$-cyclodextrin: Evaluation of different complexation methods. Drug Dev Ind Pharm 1993;19:875-85.

8. Nagase Y, Hirata M, Wada K, Arima H, Hirayama F, Irie T, et al. Improvement of some pharmaceutical properties of DY-9760e by sulfobutyl ether beta-cyclodextrin. Int J Pharm 2001;229:163-72.
9. Moyano JR, Arias MJ, Gines JM, Perez JI, Rabasco AM. Dissolution behavior of oxazepam in the presence of cyclodextrins: Evaluation of oxazepam dimeb binary system. Drug Dev Ind Pharm 1997;23:379-85.

10. Castillo JA, Palomo-Canales J, Garcia JJ, Lastres JL, Bolas F, Torrado JJ, et al. Preparation and characterization of albendazole betacyclodextrin complexes. Drug Dev Ind Pharm 1999;25:1241-8.

11. Díaz D, Escobar Llanos CM, Bernad Bernad MJ. Study of the binding in an aqueous medium of inclusion complexes of several cyclodextrins involving fenoprofen calcium. Drug Dev Ind Pharm 1999;25:107-10.

12. Stella VJ, Rajewski R. Derivatives of Cyclodextrins Exhibiting Enhanced Aqueous Solubility and Pharmaceutical use Thereof, United States Patent No. 5. 1992 July 18.

13. Tam-Zaman N, Tam YK, Tawfik S, Wiltshire H. Factors responsible for the variability of saquinavir absorption: Studies using an instrumented dog model. Pharm Res 2004;21:436-42.

14. Sinko PJ, Kunta JR, Usansky HH, Perry BA. Differentiation of gut and hepatic first pass metabolism and secretion of saquinavir in ported rabbits. J Pharmacol Exp Ther 2004;310:359-66.

15. U.S. Food and Drug Administration. Invirase. Available from: http:// www.fda.gov/medwatch/SAFETY/2003/03DEC_PI/Invirase_PI.pdf.

16. Guo X, Shuang S, Wang X, Dan C, Pan J, Enein HY. Comparative study on the inclusion behavior of cyclodextrin derivatives with venoruton and rutin by thin layer chromatography. Biomed Chromatogr 2004; 18:559-63.

17. Arima H, Yunomae K, Miyake K, Irie T, Hirayama F, Uekama K, et al. Comparative studies of the enhancing effects of cyclodextrins on the solubility and oral bioavailability of tacrolimus in rats. J Pharm Sci 2001;90:690-701.

18. Higuchi T, Connors KA. Phase solubility techniques. Adv Anal Chem Instr 1965:4:117-212.

19. Hirayama F, Uekama K. Methods of investigating and preparing inclusion compounds. In: Duchene D, editor. Cyclodextrins and their Industrial Uses. Paris: Editions de Sante; 1987. p. 131-72.

20. Hedges AR. Industrial applications of cyclodextrins. Chem Rev 1998;98:2035-44. 
21. Rajendrakumar K, Madhusudan S, Pralhad T. Cyclodextrin complexes of valdecoxib: Properties and anti-inflammatory activity in rat. Eur J Pharm Biopharm 2005;60:39-46.

22. Maa YF, Nguyen PA, Andya JD, Dasovich N, Sweeney TD, Shire SJ, et al. Effect of spray drying and subsequent processing conditions on residual moisture content and physical/biochemical stability of protein inhalation powders. Pharm Res 1998;15:768-75.

23. Andya JD, Maa YF, Costantino HR, Nguyen PA, Dasovich N, Sweeney TD, et al. The effect of formulation excipients on protein stability and aerosol performance of spray-dried powders of a recombinant humanized anti-igE monoclonal antibody. Pharm Res 1999; $16: 350-8$.

24. Foster TP, Leatherman MW. Powder characteristics of proteins spray-dried from different spray-dryers. Drug Dev Ind Pharm 1995;21:1705- 23.

25. Maa YF, Costantino HR, Nguyen PA, Hsu CC. The effect of operating and formulation variables on the morphology of spray-dried protein particles. Pharm Dev Technol 1997;2:213-23.

26. Broadhead J, Rouan SK, Hau I, Rhodes CT. The effect of process and formulation variables on the properties of spray-dried b-galactosidase. J Pharm Pharmacol 1994;46:458-67.

27. Dunbar CA, Concessio NH, Hickey AJ. Evaluation of atomization performance in production of respirable spray-dried particles. Pharm Dev Tech 1998;3:433-41.

28. Fukuda M, Miller DA, Peppas NA, McGinity JW. Influence of sulfo butyl ether $\beta$-cyclodextrin on the dissolution properties of a poorly soluble drug from extrudates prepared by hot-melt extrusion. Int $\mathrm{J}$ Pharm 2008;350:188-96.

29. United States Pharmacopoeia 30-National Formulary 25. Twin Brook Parkway, Rockville. USA: United States Pharmacopoeial Convention Inc.; 2007. p. 3143.

30. U.S. Food and Drug Administration. Recommended Dissolution Methods. Available from: http:/www.accessdata.fda.gov/scripts/cder/ dissolution/index.cfm.

31. Pathak SM, Musmade P, Dengle S, Karthik A, Bhat K, Udupa N, et al. Enhanced oral absorption of saquinavir with methyl-beta-cyclodextrinpreparation and in vitro and in vivo evaluation. Eur J Pharm Sci 2010;41:440-51 